\title{
POR LOS CAMINOS DE LA HISTORIA REGIONAL
}

FRANCISCO JAVIER DELGADO AGUILAR

Departamento de Historia/UAA

JESÚs GómEz SERRANo, Haciendas y ranchos de Aguascalientes. Estudio regional sobre la tenencia de la tierra y el desarrollo agrícola en el siglo XIX, México, Universidad Autónoma de Aguascalientes/ Fomento Cultural Banamex, A.C., 2000.

$\bar{F}_{\text {s }}$ necesario mencionar, antes de entrar propiamente en materia, que me considero un neófito en lo que a historia agraria se refiere, pues lo que conozco acerca del tema se reduce a lo que buenamente he logrado aprender a lo largo de mis pocos años como estudiante de historia. Por esta razón, decidí hacer una lectura no enfocada necesariamente en el contenido, sino más bien en la forma en que el autor aborda su objeto de estudio.

Mi objetivo fue encontrar elementos que me permitieran ubicar la obra en el contexto más general de la historiografía local y poder así valorar lo que creo son las principales aportaciones del autor. Además, retomo algunos argumentos desarrollados en el texto que me parecen particularmente importantes, ya sea porque sirven para comprender otros aspectos de la historia local o porque señalan asuntos que aún no han sido suficientemente investigados.

Quisiera puntualizar, además, que para realizar la presente valoración de la historiografía local sólo se tomaron en cuenta libros y artículos publicados, razón por la cual no se mencionan tesis académicas o trabajos inéditos, lo cual sería materia de un trabajo más especializado y extenso que no se intentó realizar para la presente ocasión. 
$* * *$

Han transcurrido más de cien años desde que Agustín R. González, político liberal que vivió en la entidad a mediados del siglo XIX, publicara su Historia del Estado de Aguascalientes. Este libro constituyó el primer intento por abordar de manera integral la historia del estado, desde el siglo XVI hasta 1875, año en que el autor interrumpió su narración. ${ }^{1}$

A este trabajo pionero, influido profundamente por el ambiente historiográfico de la época y en muchos aspectos limitado por las manías personales del autor, se unieron posteriormente las importantes aportaciones de gente como Jesús Bernal Sánchez y, sobre todo, Alejandro Topete de Valle, cuyos principales esfuerzos estuvieron dedicados a la recopilación y publicación de documentos inéditos esenciales para el conocimiento de la historia local.

Lo que podría denominarse como profesionalización de la práctica historiográfica comenzó, así fuera de

1 El libro de Agustín R. González se publicó por primera vez en 1881. La edición más reciente del mismo es del Instituto Cultural de Aguascalientes, México, 1992. manera simbólica, a principios de los ochenta, con la publicación de la conocida obra de Beatriz Rojas sobre la destrucción de la hacienda en Aguascalientes. ${ }^{2}$ En cierto modo este libro constituyó un hito en la historiografía local, pues a partir de su publicación salieron a la luz una serie de estudios que se constituyeron como los primeros acercamientos a diversos aspectos de la historia del estado.

Esto resultó notorio sobre todo a principios de la década de los ochenta. Fue durante estos años, por ejemplo, cuando el historiador español Vicente Ribes Iborra publicó un conjunto de libros sobre temas tan variados como la lucha insurgente, ${ }^{3}$ la separación de Aguascalientes del estado de Zacatecas, ${ }^{4}$ la Reforma y el Porfiriato $^{5}$ y la prensa anarquista

2 Beatriz Rojas, La destrucción de la hacienda en Aguascalientes. 1910-1931, El Colegio de Michoacán, México, 1980.

3 La insurgencia en Aguascalientes, Universidad Autónoma de Aguascalientes, México, 1987.

4 Independencia del estado de Aguascalientes, 1835-1847, UNAM, México, 1981.

5 La Reforma y el Porfiriato en Aguascalientes, Universidad Autónoma de Aguascalientes, México, 1983. 
durante los años veinte. ${ }^{6}$

El mismo Jesús Gómez realizó sus primeras incursiones en la historia económica y agraria de la localidad, con libros como Aguascalientes: imperio de los Guggenheim, en donde analiza el impacto y funcionamiento de la Fundición Central Mexicana en el estado a principios del siglo XX. ${ }^{7}$ A esta obra habría que agregar otras más sobre la hacienda del Ojocaliente, ${ }^{8}$ el mayorazgo de los Rincón Gallardo y los orígenes de la feria de Aguascalientes. ${ }^{10}$

Beatriz Rojas, por su parte, enfocó su atención a algunos aspectos de la época colonial y publicó artículos sobre la testamentaría de los hermanos Rincón Gallardo; el cultivo

6 Prensa Anarquista de Aguascalientes, 1922-1926, Universidad Autónoma de Aguascalientes, México, 1980.

7 Aguascalientes; Imperio de los Guggenheim, Fondo de Cultura Económica/Secretaría de Educación Pública, México, 1982.

8 Ojocaliente: una hacienda devorada por la urbe, CIRA, México, 1983.

9 El Mayorazgo Rincón Gallardo. Disolución del vínculo y reparto de las haciendas, México, CIRA, 1984.

10 Mercadenes, artesanos y toreros. La feria de Aguascalientes en el siglo XIX, Aguascalientes, Instituto Cultural de Aguascalientes, México, 1985. de la vid y la fabricación de chinguirito y la fundación de los diversos pueblos de indios localizados en el territorio de la entonces alcaldía de Aguascalientes. ${ }^{11}$

A lo anterior habría que agregar la obra en 4 tomos y 7 volúmenes escrita por Jesús Gómez Serrano en colaboración con Enrique Rodríguez Varela, Aguascalientes en la Historia, que en su conjunto constituye un acercamiento global a la historia del estado desde fines del siglo XVIII hasta 1920 y que toma en cuenta no sólo aspectos políticos sino también económicos, sociales y culturales. ${ }^{12}$

La actividad historiográfica recibió un impulso definitivo a principios de los noventa. Durante estos años se publicaron, por ejemplo, los libros de Yolanda Padilla sobre el movimiento cristero ${ }^{13}$ y el conflicto

11 Estos y otros artículos de Beatriz Rojas se encuentran recopilados en: En los caminos de la historia. Aguascalientes en el siglo XVIII, CIEMA, México, 1999.

12 Aguascalientes en la Historia, 1786 1920,4. Tomos/7 Volúmenes, Gobierno del Estado de Aguascalientes/Instituto de Investigaciones José María Luis Mora, México, 1988.

13 El catolicismo social y el movimiento cristero en Aguascalientes, Instituto Cultural del Aguascalientes, México, 1992. 
religioso en Aguascalientes durante los años setenta. ${ }^{14}$ Otra contribución importante fue la de Víctor González, que en el año de 1992 publicó una obra de nombre Jalones Modernizadores: Aguascalientes en el siglo $X X$, en la cual trató temas como la tenencia de la tierra en vísperas de la revolución mexicana, la transición demográfica ocurrida en el estado durante el siglo XX y la reforma agraria entre los años de 1915 y $1940 . .^{15}$

Habría que mencionar también el libro de Carlos Reyes Sahagún sobre los orígenes y el desarrollo del movimiento obrero cetemista local; ${ }^{16}$ el de Salvador Camacho sobre la educación socialista; ${ }^{17}$ el de Andrés

14. Con la Iglesia hemos topado. Catolicismo y Sociedad en Aguascalientes. Un conflicto de los años 70's, Instituto Cultural de Aguascalientes, México, 1991.

15 Jalones Modemizadores. Aguascalientes en el siglo $X X$, Instituto Cultural de Aguascalientes, México, 1992.

16 El movimiento Obrero Cetemista en Aguascalientes. 1937-1962, Instituto Cultural de Aguascalientes, México, 1993.

17 Controversia educativa entre la ideología y la fe. La educación socialista en la historia de Aguascalientes, 1876-1940, Consejo Nacional para la Cultura y las Artes, México, 1991.
Reyes, que estudia la historia electoral de la entidad a partir de $1940^{18} \mathrm{y}$, en fin, el libro de Jesús Gómez acerca del proceso que llevó a Aguascalientes a separarse de Zacatecas y consolidarse como estado independiente. ${ }^{19}$

Como la simple enumeración de títulos y autores no lleva propiamente a ningún lado, conviene señalar algunas de las características que comparten la mayoría de las obras aquí citadas. El rasgo más obvio y que salta rápidamente a la vista es que la mayoría constituyen acercamientos monográficos a temas o aún a acontecimientos muy específicos de la historia local. Sea el caso por ejemplo, del escándalo provocado por el descubrimiento de que la mayoría de los habitantes de Aguascalientes se dedicaba a la fabricación ilegal de chinguirito a fines del siglo XVIII; la disolución del mayorazgo de Ciénega de Mata; la instalación en la capital de la Fundición Central Mexicana o la publicación de periódicos de corte anarquista.

18 ¿Elecciones o designaciones? 50 años de Historia Electoral en Aguascalientes, México, 1993.

19 La creación del estado de Aguascalientes. (1786-1857), Consejo Nacional para la Cultura y las Artes, México, 1994. 
Una característica importante relacionada con la anterior es que en varios casos los autores desarrollan en un mismo volumen asuntos que no tienen una conexión directa, aunque pueden estar vinculados a un interés o temática general. Así, en su libro titulado Hacendados y campesinos en Aguascalientes, Jesús Gómez aborda en capítulos independientes temas como la legislación agraria estatal; la situación de las haciendas de Paredes y Pabellón y la lucha por la tierra del pueblo de indios de Jesús María. ${ }^{20}$

Otro ejemplo es el de Yolanda Padilla, que en un solo libro $-E I$ catolicismo social y el movimiento cristero- analiza por separado dos temas que no dejan de tener una estrecha relación: por una parte el desarrollo del catolicismo social en Aguascalientes a fines del siglo XIX y principios del XX y por la otra el impacto que tuvo en el estado el movimiento cristero a fines de los años veinte.

Un caso extremo lo constituye uno de los libros de Vicente Ribes, que en una primera parte describe el periodo de la Reforma en

20 Hacendados y campesinos en Aguascalientes, CIRA, México, 1985.
Aguascalientes para después saltarse sin más a la época del Porfiriato, sin tomar en cuenta en lo absoluto el tramo de la República Restaurada.

Estamos pues, ante una historiografía local compuesta principalmente por acercamientos monográficos a temas y problemas muy específicos y que en la mayoría de los casos se desarrollan en cortos periodos de tiempo. Además, en muchos casos las obras carecen de un argumento o hilo conductor central, pues están compuestas por capítulos que no tienen una conexión explícita, al menos para el lector no especializado.

A últimas fechas han comenzado a salir a la luz una nueva serie de investigaciones que tomando como fundamento lo que se ha realizado en años anteriores proponen un acercamiento diferente a los diversos problemas que plantea la historia local. Se trata de estudios en cierta manera más ambiciosos, que no sólo abarcan periodos extensos de tiempo, sino que también apuestan por conseguir una comprensión global de su objeto de estudio.

En este caso se encuentran, por ejemplo, dos libros recientemente publicados por José Antonio Gutiérrez: La Labor Social de la 
Iglesia Católica ${ }^{21}$ y Aguascalientes y su región de influencia hasta $1810 .{ }^{22}$ En el primero, el autor abarca un periodo de tiempo que va desde mediados del siglo XIX hasta la época actual, mientras que en el segundo, parte de la época prehispánica y llega hasta fines del periodo colonial, en un estudio en donde se toman en cuenta aspectos geográficos, económicos y políticos.

Un buen ejemplo lo constituye también el último libro publicado por Beatriz Rojas, Las instituciones de gobierno y la élite local, en donde la historiadora hace un detallado análisis de los principales grupos de poder de la región (hacendados y comerciantes) y su vinculación con las instituciones de gobierno local durante la época colonial. ${ }^{23}$

21 La labor social de la iglesia católica en Aguascalientes, Instituto Cultural de Aguascalientes, México, 1997.

22 Aguascalientes y su región de influencia hasta 1810. Sociedad y política, Sistema de Educación Media Superior de la Universidad de Guadalajara/Amigos de la Historia de los Altos de Jalisco, México, 1998.

23 Las instituciones de gobiemo y la élite local. Aguascalientes del siglo XVII hasta Ia Independencia, El Colegio de Michoacán/Instituto Mora, México, 1998.
Estamos, en estos casos, ante obras que además de abarcar amplios periodos de tiempo ofrecen al lector una visión más comprehensiva y coherente de la temática abordada, pues a diferencia de libros anteriores, no son simplemente estudios monográficos sin una conexión explícita, sino que manejan un argumento central.

Otro rasgo importante de estos nuevos estudios es que toman en cuenta de una manera decisiva el contexto nacional y lo relacionan con lo sucedido localmente. Este es el caso del libro más reciente de Víctor González sobre la revolución mexicana en Aguascalientes, en donde la investigación documental basada en fuentes de primera mano se enriquece con una amplia perspectiva que combina el largo plazo con lo sucedido a nivel nacional para así aportar nuevos elementos que contribuyen a una mejor comprensión de lo sucedido en Aguascalientes durante esos años. ${ }^{24}$

24. Cambio y Continuidad. La Revolución Mexicana en Aguascalientes, CIEMA/ Gobierno del Estado, México, 1998. 
incorporar nuevos elementos de análisis posee, según mi particular El libro de Jesús Gómez, Haciendas y Ranchos en Aguascalientes, se inscribe en esta nueva serie de trabajos de historia regional, pues apoyado en una vasta investigación en archivos estatales, nacionales y privados, se ocupa de estudiar a fondo y durante un periodo de tiempo prolongado el problema de la tenencia de la tierra y el desarrollo agrícola.

Como en el caso de Beatriz Rojas o Víctor González, este libro es en buena medida, el resultado final de una serie sucesiva de acercamientos de carácter monográfico a temas tan diversos como la creación de pueblos de indios, la fragmentación de haciendas, el proceso de industrialización que experimentó el Estado a fines del siglo.XIX, el crecimiento de la ciudad capital o la situación los trabajadores de las haciendas.

Todos estos son aspectos que de una u otra manera ya habían sido abordados con anterioridad por el autor, quien los retoma y reincorpora en su libro más reciente. Es importante recalcar, sin embargo, que no estamos ante una simple recopilación de trabajos anteriores, pues lo que Jesús Gómez nos ofrece ahora es una historia social de la tenencia de la tierra que al

criterio, un potencial explicativo mucho mayor al de sus anteriores trabajos sobre el mismo tema.

Entre estos nuevos elementos de análisis me gustaría mencionar dos, que considero cruciales. El primero se refiere a la conexión entre historia nacional e historia regional. A lo largo del libro se establece entre ambos elementos una compleja relación dialéctica, pues el autor parte de la idea de que los "procesos históricos que afectan a buena parte del país" durante el siglo XIX, como la fragmentación de las haciendas, la consolidación de la propiedad ranchera y la modernización parcial de las prácticas agrícolas, entre otros . muchos, tuvieron "una expresión regional específica".

De esta manera, se combina el enfoque monográfico, que permite conocer en detalle la historia agraria de la región, "con el seguimiento de las tendencias generales que se observan en el campo de la tenencia de la tierra a lo largo del siglo XIX". Esto da al libro de Jesús Gómez la perspectiva adecuada no sólo para valorar en sus justas dimensiones los fenómenos que afectaron al campo aguascalentense durante el siglo 
pasado, sino que también le permite aportar una nueva serie de elementos que pueden contribuir a una mayor comprensión de ciertos aspectos de la historia agraria a nivel nacional.

Un segundo elemento que da a la obra que ahora se comenta un nuevo y mayor alcance es el concepto de región manejado por el autor. Esto es algo novedoso sobre todo en lo que respecta a los libros de historia publicados durante la década de los ochenta y los noventa, pues casi en todos ellos se da por descontado que los límites administrativos del estado de Aguascalientes demarcan un área de estudio específica y que se justifica por sí misma.

A este respecto, Jesús Gómez propone -según sus propias palabras- "una caracterización funcional de la región de Aguascalientes, que sirva como asidero de todas las consideraciones hechas a lo largo del texto". Esta región, como era de esperarse, rebasa la fronteras estatales de Aguascalientes y permite al autor, como él mismo lo menciona, combinar de una manera más efectiva el enfoque microhistórico con el análisis estructural.

En su definición de región, el autor da una gran importancia al papel jugado por la ciudad de
Aguascalientes. Esta aparece, a lo largo de todo el estudio, como el epicentro de la vida económica, política y social del área estudiada, su principal elemento articulador. Así, en el siglo XIX y ante la decadencia de la actividad minera de Zacatecas, la ciudad capital se convirtió en el principal mercado de los productos agrícolas y ganaderos producidos por las haciendas circunvecinas. Esta situación se hizo aún más notoria hacia fines del Porfiriato, cuando gracias al marcado crecimiento demográfico y a la expansión urbana, producto del proceso de industrialización, la ciudad se consolidó como un "auténtico detonador del potencial agrícola de la región".

La gran importancia de la ciudad también ha sido señalada por Víctor González, quien en un artículo sobre Aguascalientes en la época de la independencia menciona que fue precisamente la concentración de la población en la villa uno de los factores que influyó para que la subdelegación se mantuviera al margen de la violencia provocada por la lucha insurgente. ${ }^{25}$

25 Víctor Manuel González Esparza, Espacio 
A pesar de lo anterior no existen, hasta donde se sabe, estudios que se ocupen de analizar el desarrollo y la estructura urbana de la ciudad de Aguascalientes durante la época colonial y el siglo XIX. Sería muy importante a este respecto, por ejemplo, una historia demográfica que a partir del manejo sistemático de fuentes de prinera mano otorgara una visión de la población urbana, lo cual serviría para confirmar o en su caso matizar lo que hasta ahora se ha sostenido a partir del análisis de fuentes dispersas y cualitativas: que la ciudad de Aguascalientes, con ciertas interrupciones provocadas por las epidemias, experimentó un constante aumento en el número de sus habitantes. Esto es importante en tanto que fue precisamente el crecimiento demográfico lo que permitió a la ciudad convertirse en el principal mercado de los productos agrícolas de la región.

Otra veta que puede resultar fructífera a la hora de abordar la historia de la ciudad es el estudio de las huertas, que fueron parte esencial del paisaje urbano durante casi todo

regional y Estado Nación, CIEMA/UAA, México, 1999. el siglo XIX. Las huertas, tal y como lo menciona Jesús Gómez, tanto en el libro que ahora se presenta como en otras de sus obras, constituían no solo "un rasgo pintoresco de la ciudad, sino un medio de vida para muchos de sus habitantes". La presencia de las huertas, además, determinaba la estructura y organización de la ciudad e influía profundamente en el abasto de agua.

Un análisis que se ocupara del proceso de desarrollo y decadencia de las huertas en la ciudad de Aguascalientes otorgaría elementos útiles para caracterizar con mayor exactitud problemas como el crecimiento de la ciudad; el peso político y económico de los dueños de las huertas; las formas en que se legislaba el uso del agua; el control de los recursos hidráulicos por parte de las élites a través de instituciones como el ayuntamiento o la jefatura política; el impacto político y social que tuvo en Aguascalientes la instalación de grandes talleres y fábricas a fines del siglo XIX y las modificaciones de la traza urbana, aspectos que nos permitirían conocer con mayor profundidad la historia económica, política y social de la ciudad de Aguascalientes, señalada por Jesús Gómez como el principal 
motor del desarrollo agrícola de la región.

El libro de Jesús Gómez, aunque resulta esencialmente un estudio de historia económica y social, aporta claves muy importantes para lograr una mejor comprensión de la historia política de la localidad durante la segunda mitad del siglo XIX. Resalta a este respecto la formación e incorporación a la élite rural de la región de un grupo de "nuevos hacendados" provenientes, según expresión del autor, "de la pequeña burguesía en ascenso". Estas personas habían acumulado su capital en actividades comerciales o industriales y habían decidido invertir sus ganancias en la compra de una hacienda. Los ejemplos típicos de este nuevo grupo fueron Rafael Arellano y Antonio Morfín Vargas, cuyas ascendentes carreras son minuciosamente documentadas por el autor.

Estos "nuevos hacendados" no sólo intentaron modernizar las prácticas agrícolas en. sus propiedades, sino que pronto se consolidaron como uno de los principales grupos políticos de la entidad. Rafael Arellano, por ejemplo, fue gobernador del estado en dos ocasiones durante la época del
Porfiriato, mientras que Antonio Morfín Vargas se desempeñó como diputado local y en una ocasión aspiró a la gubernatura del estado como candidato de oposición, también durante los años de Díaz.

La influencia y el peso político de este grupo se dejaba notar principalmente a la hora de definir el régimen de finanzas estatales. Así, entre 1861 y 1912 los hacendados tuvieron la capacidad y los recursos suficientes para echar por tierra tres proyectos de leyes fiscales cuyo objetivo era aumentar las contribuciones que pagaba la propiedad rústica.

El gobernador Esteban Ávila en 1861, Jesús Gómez Portugal en 1868 y Alberto Fuentes Dávila en 1912, se enfrentaron a la beligerante oposición de los dueños de la tierra, quienes se negaban a pagar mayores impuestos. De hecho el único que pudo establecer un alza impositiva fue el gobernador porfirista Alejandro Vázquez del Mercado, en 1905, aunque para ello tuvo que llegar a un arreglo con los hacendados gracias al cual el peso de los nuevos impuestos recayó principalmente sobre los pequeños y medianos propietarios.

Su capacidad de movilización a la hora de evitar el pago de imposiciones 
y el control que ejercían en el aparato político mediante el desempeño de los cargos públicos, convirtieron a estos hacendados en un importante grupo de poder local, opuesto en cierta medida a la facción dirigida por el gobernador porfirista Alejandro Vázquez del Mercado.

A partir de la década de 1880 se estableció entre ambas facciones un delicado equilibrio político que permitió mantener en el estado un ambiente de orden y progreso económico. Sin embargo, y como en otras partes del país a principios del siglo XX, estos hacendados fueron progresivamente excluidos de la actividad política por el grupo encabezado por Alejandro Vázquez del Mercado. Esto provocó un profundo descontento que dio origen en 1911 a la movilización de un grupo de propietarios y miembros de la clase media que tenían como objetivo llevar una vez más a Rafael Arellano a la gubernaturà del estado.

Momentáneamente interrumpida por el triunfo de la revolución, la campaña de los arellanistas continuó a lo largo de la segunda mitad de 1911 para evitar la elección como gobernador del maderista Alberto Fuentes Dávila, cuyo apoyo provenía principalmente de los campesinos y los grupos de clase baja. Los arellanistas no pudieron impedir el triunfo del líder maderista, pero lograron hacerse de posiciones en el congreso local y tuvieron la capacidad suficiente para impedir que Fuentes Dávila gobernara con libertad.

Finalmente, quisiera mencionar la importancia que tuvo la consolidación, a fines del Porfiriato, de una clase media propietaria compuesta principalmente por rancheros y aparceros. La conformación y fortalecimiento de esta clase media, que es uno de los principales argumentos sostenidos por Jesús Gómez a lo largo de todo el libro, resulta esencial a la hora de explicar la ausencia de movimientos armados en el estado durante la Revolución, pues aunque no se pueden negar los altos índices de concentración de la propiedad existentes en Aguascalientes a principios de siglo, es probable que la existencia de esta clase media haya contribuido en buena medida a disminuir la tensiones agrarias, al funcionar como una especie de amortiguador entre la élite propietaria y la gran masa de desposeídos.

El libro de Jesús Gómez, Haciendas y Ranchos de Aguascalientes, representa pues, no sólo la brillante culminación de muchos años de 
trabajo dedicados al estudio de la historia agraria de la localidad, sino también una aportación fundamental a la historiografía local, pues aparte de contribuir a una mejor comprensión de la historia de la región de Aguascalientes en el siglo XIX, abre nuevas perspectivas de investigación y propone temas que será necesario investigar en un futuro no muy lejano. 